\title{
EXPERIENCIAS TRANSICIONALES Y MENTALIZACIÓN ${ }^{1}$
}

\author{
Francesc Saínz Bermejo² \\ SEP-IPA, IPR, AWB
}

En los procesos de mentalización intervienen elementos cognitivos, emocionales e incluso somáticos, vinculados a través de las experiencias relacionales. Para Winnicott los cuidados infantiles continuados permiten al niño unificar las sensaciones corporales con las emociones, si la experiencia es suficientemente buena, la mente se deja ir con confianza. Cuando el niño no se siente sostenido ni recogido en su emocionalidad, la mente se hipertrofia y se aleja de la unidad psicosomática, aparece entonces el funcionamiento concreto. La figura materna ejerce la función de espejo a través del cual el niño puede verse a sí mismo. El adulto se deja mirar en su interior y de esta forma el niño empieza a sentir que él mismo también posee una interioridad. Las experiencias transicionales entre el niño y sus adultos representan la construcción compartida de la identidad y son la base en la que se asientan los procesos de mentalización.

Palabras clave: Experiencias transicionales, mentalización, espacio intersubjetivo, pensamiento concreto, especularidad, hipertrofia mental.

Cognitive, emotional and even somatic elements intervene in mentalization processes linked through relational experiences. For Winnicott, continue childcare allows children to unify body sensations with emotions: if the experience is good enough, the mother lets go with confidence. When the child is neither feeling sustained nor collected in his/her emotionality, the mind hypertrophies and moves away from the psychosomatic unit, then concrete functioning takes place. The mother figure exercises the mirror function through which the child can see himself/herself. The adult allows himself/herself to look inside and in this way the child begins to feel that he/she also has an interiority. The transitional experiences between the children and their adults represent the shared construction of identity and the foundation on which the process of mentalization relays.

Key Words: Transitional experiences, mentalization, intesubjective space, concrete thinking, specularity, mental hypertrophy.

ENGLISH TITLE: Transitional Experiences and Mentalization

\section{Cita bibliográfica / Reference citation:}

Saínz, F. (2017). Experiencias transicionales y mentalización. Clínica e Investigación Relacional, 11 (1): 93-100. [ISSN 1988-2939] [Recuperado de www.ceir.info] DOI: 10.21110/19882939.2017.110105

\footnotetext{
${ }^{1}$ Trabajo basado en el texto presentado en las IV jornadas de Psicoanálisis Relacional, organizadas por el Instituto de Psicoterapia Relacional (Salamanca, 28-29 octubre de 2016)

${ }^{2}$ Francesc Sáinz Bermejo es Psicoanalista de la SEP/IPA. Miembro titular del IPR. Presidente de la Asociación Winnicott Barcelona. Autor de la obra: Winnicott y la perspectiva relacional en psicoanálisis (Barcelona: Herder, 2017) y de otros trabajos sobre el pensamiento e influencia de Winnicott. Dirección de contacto: francescsainz@gmail.com
}

\section{CeIR Vol. 11 (1) - Febrero 2017 ISSN 1988-2939 - www.ceir.info}

(c) Derechos reservados/Copyright de Clínica e investigación Relacional y los autores. Prohibida la reproducción total o parcial sin autorización expresa. Este material es para uso científico y profesional exclusivamente y puede contener información clínica sensible. Los editores no se responsabilizan de los contenidos de los autores. Dirigir las consultas sobre derechos y autorizaciones a ceir@psicoterapiarelacional.es 
En el proceso de mentalización se entrelazan diversos factores de carácter cognitivo, emocional e incluso somático, todo ello vehiculizado por las experiencias relacionales. El trabajo de Winnicott de 1949. "La mente y su relación con el psique-soma", nos permite entender las interacciones necesarias que preparan la capacidad para la mentalización. La psique representa, para Winnicott, la emocionalidad. Las emociones están directamente unidas a las experiencias corporales del bebé. Mientras la mamá cuida el cuerpo, a la vez está cuidando la vida emocional del niño. Para ello necesita recurrir a su capacidad de "reverie" y a su sensibilidad derivada de la "preocupación maternal primaria", de esta forma se establecerán los nexos que unen lo somático con lo emocional. La mente, entonces, podrá estar lo más tranquila posible y se dejara llevar con confianza. Si los cuidados son suficientemente buenos, la actividad mental se entrega a ellos y es entonces cuando se produce la experiencia integrativa entre cuerpo, emoción y una mente que se ubica sin demasiada presencia ni actividad. La mente se va con el cuerpo ("surrender"), en el que poco a poco se van organizando las emociones Cuando la criatura no se siente sostenida y cuidada, los peligros aumentan y con ellos la necesidad de defenderse de ellos. Es entonces cuando la mente hace su presencia, en lugar de dejarse ir con confianza, se activa y aumenta la capacidad de controlar las experiencias; de alguna manera podemos decir que se hipertrofia. La mente hiperactivada y controladora traba las conexiones fluidas entre el soma, la emoción y las cogniciones. Podríamos decir que "mucha mente, impide la mentalización". Según los estudios actuales de neurociencia en los momentos en los que el cerebro está menos activado es cuando el sujeto lleva a cabo actividades más productivas y eficaces, puede que más creativas también.

La patología obsesiva, paranoide, narcisista, ciertas formas psicosomáticas, el trastorno límite, entre otros, cuentan con un funcionamiento hipertrófico de la mente que tiene la característica fundamental de un pensamiento concreto. No olvidemos que muchas de estas estructuras se han ido organizando como una forma adaptativa de hacer frente a las carencias afectivas. Se genera entonces un pensamiento desconectado de la emocionalidad y de las vivencias, con escasa capacidad para sentir y expresar los sentimientos; en realidad con escasa capacidad para la mentalización.

Que el niño se sienta en peligro de aniquilación o lo que Bion llama, ansiedades catastróficas, no depende de la pulsión de muerte en primacía de la pulsión de vida, sino de sus experiencias relacionales vivenciadas con sus cuidadores principales. Cuentan las capacidades del sujeto para soportar la frustración y encontrar salidas adaptativas y las capacidades de los cuidadores para comprender, sostener y cuidar de forma adecuada a su niño. 
Los cuidadores ofrecen al bebé unos brazos seguros donde sostenerse, y también le prestan una mente que puede pensar y sentir lo que la criatura está viviendo, también le prestan un falso self, al que yo llamaría protector del self, para defenderse y adaptarse de la mejor manera posible.

Cuando el sufrimiento es excesivo y las capacidades adaptativas fallan, se puede instalar lo que Winnicott llama "una huida hacia la realidad.". Un exceso de realidad causado por experiencias traumáticas, fija el trauma e impide desprenderse del dolor. Fonagy entiende que las experiencias traumáticas detienen y pulverizan la capacidad de mentalizar. Huir hacia la realidad es un intento de controlar los efectos devastadores de ésta.

La huida hacia la fantasía, es también otro modo de defenderse de la cruda realidad, sin embargo la fantasía que se edifica cuando el pequeño no se ha sentido protegido por sus cuidadores, tiende a ser una fantasía alejada de la experiencia y por lo tanto no se caracteriza por su función simbólica. Winnicott llama a este fenómeno "fantaseo" que tiene un sentido peyorativo. Tanto la mente controladora que huye hacia la realidad, como la mente que usa el fantaseo de una forma no simbólica, no tiene acceso a la función de la mentalización.

Es evidente que la realidad sin filtros produce un impacto emocional, por lo que todo lo que ha resultado traumático y no ha podido ser vehiculizado por los cuidadores, tiende a romper los nexos que unen las experiencias. Lo sensorial, lo cognitivo se desliga de lo emocional y de lo somático, a la vez que los sentimientos y los afectos no encuentran un lugar donde ubicarse y donde expresarse. Para Winnicott el trauma más difícil de situar es el que no ha sucedido, que ha quedado implícito en el mundo experiencial, pero el sujeto no puede referirse a él. Para ello se deben dar las condiciones óptimas que hagan posible su emergencia y siempre debe darse dentro de una experiencia relacional y vincular. (Véase el "Miedo al derrumbe", 1963)

Las experiencias transicionales permiten filtrar la realidad de una forma que no dañe las capacidades originales, próximas a la creatividad. Los procesos de ilusión y desilusión generan espacios mentales que si son atendidos por cuidadores sensibles y que garantizan su continuidad, se convierten en espacios potenciales y transicionales, cuya característica principal es la flexibilidad y la tolerancia de lo incierto. No se puede entender todo, ni comprender el sentido de todo, solo se puede confiar en que alguien entiende un poco más que yo y me ayuda a ser el constructor de mi propia vida, aunque en realidad poco a poco descubro que de mi identidad, como mucho, soy coautor.

La inmensa riqueza de las experiencias transicionales reside en que no hay una 
imposición, un protocolo que seguir. La figura adulta cuidadora se sumerge en una relación con su pequeño, sin miedo a la fusión ni a la confusión. Dispuesta a aprender del niño, escuchándole y escuchándose a sí misma. Es preciso contar con la flexibilidad suficiente para poder rectificar y ser capaz de aceptar no ser una figura perfecta, sino suficientemente buena que incluye al mismo tiempo la insuficiencia.

El mundo es excesivo para un ser humano recién nacido. Es necesario tener a alguien adulto que se lo vaya acercando poco a poco. El bebé humano es así de inerme y de indefenso, por lo que necesita de una figura de apego, que lo alimente, que lo arrulle y que le preserve del dolor. El sufrimiento y la frustración son inevitables, pero sí se puede y se debe evitar un exceso de ambos.

Para conseguir que el recién nacido pueda disfrutar de una experiencia compartida y a la vez co-creada, es necesario que el adulto sea capaz de jugar. Si a la criatura se le facilita la expresión libre de su gesto espontáneo, éste desarrollará su propia capacidad de jugar, ya que ésta se dará de forma natural. El adulto debe salir a su encuentro, sin interrumpir su espontaneidad.

El espacio potencial es creado por la figura materna y por el propio niño, pertenece al universo de las experiencias compartidas, es posible porque en dicho espacio tiene lugar el juego. El espacio transicional es donde se ubica la capacidad para jugar, pero a la vez, es el jugar el que hace posible que dicho espacio exista.

Las experiencias transicionales son el paradigma de la subjetividad. El espacio transicional se encuentra a medio camino de la subjetividad de los dos participantes, ambos son coautores. Uno puede crear porque existe alguien que aproxima lo creado. A la vez la identidad del uno depende en gran parte de la identidad del otro.

Las experiencias transicionales representan por tanto la intersubjetividad y sugiero que el espacio transicional es en realidad un espacio intersubjetivo.

Cuando el cuidador trata de imponer la objetividad pura a la relación con su pequeño, interviene la lógica y no es capaz de llevar a cabo una función empática, obliga a éste a defenderse con un pensamiento desconectado y concreto. Podemos afirmar que las bases que hacen posible la mentalización y la función reflexiva imprescindible para el trabajo terapéutico, las encontramos en las experiencias transicionales. Solo un adulto consciente de que su capacidad parar pensar y sentir son subjetivas, puede reconocer y respetar la subjetividad del otro, ahora de su pequeño. Trataremos de argumentar la relación entre mentalización y experiencias transicionales más adelante. 
Creemos en la importancia que tiene el sentimiento de pertenecer a alguien para llegar a ser uno mismo. Partimos de la hipótesis de que el entorno adecuado que protege al niño, le permite la experiencia de pertenecer a alguien con la condición de poder desprenderse poco a poco de esa dependencia y sentirse real. Para Winnicott la dependencia en el principio del desarrollo humano, es absoluta y se va transformando progresivamente en relativa. Si la criatura no está protegida y bien cuidada, puede seguir buscando personas que le proporcionen la experiencia de pertenencia. La necesidad de ser de alguien, para ser alguien, al precio de sacrificar el self verdadero que ha tenido pocas y no afortunadas condiciones para desarrollarse en libertad, es el fundamento del sometimiento. El sometimiento a alguien puede ser una forma de masoquismo (Ghent, 1990) que se ha ido construyendo a partir de la necesidad de existir para los demás.

Es probable que la capacidad de mentalizar provenga de la historia del humano primitivo que necesitaba sobrevivir a los peligros que venían del exterior, para ello le era necesario tratar de leer la mente de su adversario y así anticiparse a sus intenciones. Así se instala en la filogénesis la capacidad para comprender y leer la mente del otro. "Si yo leo la mente del otro, el otro también puede leer la mía". Sobrevivir es el principio de la adaptación en la línea evolucionista y probablemente es el cimiento fundamental en el que se edifica el Psicoanálisis Relacional.

En general los humanos solemos tener el deseo de conocer la mente propia y la ajena, probablemente el orden de búsqueda sea primero conocer al otro, con el que estoy y de quien dependo, para saber que manos son las que me sostienen. El conocimiento del otro me remite al conocimiento de mí mismo y me conduce a darme cuenta de que yo también tengo un interior mental, emocional e intencional propio.

Winnicott dice:

Podemos decir que en esta fase un bebé, en sus juegos, adquiere la capacidad para demostrar que comprende que tiene un interior y que las cosas proceden del exterior. Demuestra que sabe que se ve enriquecido por lo que incorpora (física y psíquicamente). Más aún, demuestra que sabe que puede librarse de algo cuando ha obtenido de este algo lo que de él desea. Todo esto representa un tremendo avance. Al principio solamente se alcanza de vez en cuando y cada uno de los detalles de este avance puede perderse en forma de recesión debida a la angustia. El corolario de esto es que ahora el pequeño da por sentado que su madre también posee su interior, que puede ser rico o pobre, bueno o malo, ordenado o confuso. Así, pues, el pequeño empieza a preocuparse por la madre y su cordura y sus estados de ánimo. En el caso de muchos niños, a los seis meses existe una 
relación como la que hay entre las personas normales. Ahora bien, cuando un ser humano siente que es una persona relacionada con los demás, entonces es que ya ha viajado mucho desde su primitivo desarrollo. (1945, p. 203)

La figura cuidadora principal ofrece al niño la función de un espejo, no al que se mira, sino dentro del cual se mira. Para Winnicott (1968) cuando el bebé mira el rostro de su madre, y especialmente sus ojos, se ve así mismo. La figura adulta debe poder devolver en esencia lo que el propio niño tiene dentro de sí mismo, es la forma que el mirar del afuera, se convierte en un mirar del adentro.

El espejo para Winnicott es algo vivo que recibe y emite al mismo tiempo y es tridimensional. Si se produce está experiencia interactiva y conectada, la criatura puede desarrollar su capacidad para mirar fuera y dentro de sí mismo. Justamente el fundamento de la mentalización.

Conectar las vivencias, con las emociones que se convierten en sentimientos y fantasías, solo es posible en la interacción humana. Los nexos que unen cada uno de estos procesos permiten pensar sobre ellos.

\section{Cómo podemos potenciar que el espacio terapéutico sea generador de experiencias transicionales.}

Procuramos que nuestro paciente encuentre un lugar donde le es posible sentir, cuando puede hacerlo, tratamos de ayudarle a pensar y algunas veces, no siempre, logramos comprender con él. Algunas figuras maternas-paternas han sido capaces de cuidar de sus pequeños, atendiéndoles en sus necesidades corporales e incluso emocionales, pero no han sabido o no han podido leer de forma sintónica, los estados emocionales de la criatura. Tal vez no han sido capaces de dejarse penetrar por su niño, mostrando su interior para que éste pudiera conectar con el suyo propio.

Los que nos dedicamos a este oficio desde hace varias décadas sabemos que muchos son los pacientes a los que les va a costar llevar a cabo una mentalización provechosa.

Los llamados alexitímicos (Sifneos, 1973), los que tienen un pensamiento operatorio y tendencias psicosomáticas (Marty, M'uzan 1963). También los que Freyberger (1977) llama alexítimicos secundarios, cuyo funcionamiento mental era saludable hasta que tuvieron un trauma que interrumpió su mentalización, como una forma de defenderse de sus consecuencias.

Si nuestros pacientes se encuentran entre aquellos en los que su estructura mental se ha

CelR Vol. 11 (1) - Febrero 2017 ISSN 1988-2939- www.ceir.info

(c) Derechos reservados/Copyright de Clínica e investigación Relacional y los autores. Prohibida la reproducción total o parcial sin autorización expresa. Este material es para uso científico y profesional exclusivamente y puede contener información clínica sensible. Los editores no se responsabilizan de los contenidos de los autores. Dirigir las consultas sobre derechos y autorizaciones a ceir@psicoterapiarelacional.es 
organizado de forma operativa, les será muy difícil poner en marcha la función reflexiva que lleve a la mentalización. Los que tuvieron adecuadas experiencias transicionales en la infancia y algún evento o pequeños eventos continuados devastaron su salud mental, podemos ayudarles a recuperar la función mentalizadora más fácilmente.

También tenemos pacientes que presentan lo que he llamado "ángulos ciegos de su personalidad". Contenidos mentales no reconocidos, inexistentes para la persona. Puede verlos en otros sujetos, sin que sea fruto de su proyección, pero no puede verlos dentro de sí. Puede ser que este paciente, si es del oficio, sea un buen terapeuta, agudo y sutil que muestra a sus pacientes contenidos que él mismo no puede reconocer en sí mismo.

¿Qué hacemos entonces?. El paciente no puede hablar de lo que no existe, solo puede mostrarlo a través de la relación. El terapeuta puede ir acercando lo que va sintiendo y entendiendo del paciente, con el fin de que éste lo haga suyo y pueda reflexionar sobre ello.

Ya vemos que la capacidad para la mentalización tiene sus límites en muchos pacientes y, de alguna manera, en todas las personas en general. Winnicott también sabía que su comprensión era limitada, por lo que afirmaba que "a menudo interpreto para que el paciente vea los límites de mi comprensión".

La idea principal que me inspira la obra de Winnicott y que está reforzada por Orange, es que el analista ofrezca a su paciente las condiciones para que se pueda dar una experiencia nueva que recoja la antigua. Incluye que el terapeuta debe estar dispuesto a fallar a su paciente y reconocerlo como tal. A partir de lo viejo, pueden ir sucediendo pequeñas nuevas experiencias, que de alguna manera amplíen el mundo experiencial del paciente. No se trata, por lo tanto, de una experiencia totalmente nueva, sino de una experiencia vieja y conocida en la que se incluyen elementos nuevos. Poco a poco de forma implícita y a veces explícita se pueden ir abriendo las puertas que llevan a la mentalización.

Si éste adolece de cuidados emocionales básicos, debe encontrarlos, de alguna manera, en la experiencia terapéutica; si no se le ha reconocido el sufrimiento, si ha habido escasa preocupación por su persona o por sus sentimientos; si no se le permitió mirar dentro del otro para encontrarse a sí mismo o si no se le supo reconocer los errores cometidos en su crianza, de alguna manera todo ello deberá recrearse en la experiencia terapéutica, poco a poco, tal como vaya emergiendo.

Si el paciente está invadido por sus recuerdos, debemos acompañarle para que pueda olvidar, al tiempo que le ayudemos a enfrentar el sentimiento de culpa. Si necesita desgranar lo que sucedió en un momento biográfico, nuestra labor es interesarnos por su 
historia y ayudarle a hilvanar los detalles de su narrativa.

Los pacientes que cuentan con experiencias relacionales infantiles que han establecido las bases para la mentalización, les será más fácil aprovechar el trabajo terapéutico. Podremos llevar a cabo una experiencia relacional, interactiva y de recíproca mutualidad. Para las personas con poca predisposición para la mentalización, el objetivo principal de la terapia no es que mentalicen sus vivencias, sino que se les faciliten nuevas vivencias relacionales, en el vínculo terapéutico y fuera de él, para que pueda ampliar su mundo experiencial.

Debemos aceptar que siempre quedarán muchos cabos sueltos, por sentir, pensar y entender y que el terapeuta puede acompañarle como sujeto suficientemente e insuficientemente bueno, es decir, falible, o como mis colegas Abelló y Liberman dicen en su excelente libro (2011), suficientemente malo, todo ello necesario para que se produzcan pequeñas experiencias distintas y nuevas. El terapeuta debe saber jugar para ayudar a su paciente a que desarrolle su propia capacidad de juego.

\section{Unos pocos ejemplos para pensar:}

Winnicott le dijo a su paciente Margaret Little algo así: "Debo decirle, que debe saber que yo odio a su madre" (Little, 1990).

Little era médico y llego a ser psicoanalista del grupo independiente en Reino Unido, tuvo una infancia muy dura, su madre era excesivamente inestable y su padre era una persona muy poco adecuada. La intervención de Winnicott, según mi parecer, permite a Little ser reconocida en su sufrimiento, su mala relación con su madre tiene que ver en gran parte con las características de ésta. Winnicott le presta su capacidad de sentir, a la vez que le legitima su percepción, descongestionándola del sentimiento de culpa. El terapeuta presta a la paciente su capacidad de sentir y de pensar, por tanto su función mentalizadora.

Visité recientemente a una persona que había visto morir a su hija delante de ella, mientras jugaba con otros niños, la muerte aconteció de repente. Después de escuchar el relato lleno de sufrimiento y de dolor, solo pude decirle lo siguiente: "Su dolor en este momento la tiene en contacto con su hija, usted necesita sentir este dolor". La paciente contestó que el otro día su marido y su otro hijo marcharon fuera de casa durante unas horas y que fue entonces cuando ella pudo llorar y expresar su dolor sabiendo que ese momento no les haría daño a ellos. Mi intención era sobretodo legitimar su derecho a 
sentir y a expresar el daño profundo en el que se hallaba sumida.

Al acabar esa primera visita, le dije que yo podía ayudarla poco, ante algo tan doloroso que ella estaba viviendo con la muerte de su hija, pero sí que podía acompañarla y era mi deseo hacerlo. No fueron necesario más comentarios y quedamos para la siguiente vez.

\section{REFERENCIAS}

Abelló, A. y Liberman, A. (2011). Una introducción a la obra de D.W. Winnicott. Contribuciones al pensamiento relacional. Madrid: Ágora Relacional.

Freyberger H. (1977). Supportive psychotherapeutic techniques in primary and secundary alexithymia. Psychotherapy and Psychosomatics, 28: 180-190.

Little, M. I. (1990). Relato de mi análisis con Winnicott. Buenos Aires: Lugar Editorial.

Marty P, M’Uzan M. (1963). La pensée opératoire. Revue Française de Psychanalyse, 27 (suppl): $1345-1356$.

Marty, P. (1991). La psicosomática del adulto. Ed. Amorrortu. Buenos Aires

Sáinz, F. (2008). Winnicott, un buen compañero de viaje. En Liberman, A. y Abelló, A. (comp). Winnicott hoy, su presencia en la clínica actual (pp.345-359). Madrid: Psimática.

Sáinz, F. y Cabré, V. (2012). La experiencia terapéutica con un analista suficiente e insuficientemente bueno. Una contribución de Winnicott al psicoanálisis relacional, Clínica e Investigación Relacional (CeiR), 6 (3), 570-586.

Sáinz, F. (2017). Winnicott y la perspectiva relacional en Psicoanálisis. Barcelona: Herder- Fundació Vidal i Barraquer.

Sifneos PE. (1973). The prevalence of "alexithymic" characteristics in psychosomatic patients. Psychotherapy and Psychosomatics, 22: 255-262.

Winnicott, D. W. (1949). La mente y su relación con el psique-soma. New York: Basic Books, 1958.En Escritos de Pediatría y psicoanálisis, (pp.325-340). Barcelona: Paidos, 1998.

Winnicott, D.W. (1963). El miedo al derrumbe. En Exploraciones Psicoanalíticas I, Barcelona: Paidos, 2013.

Winnicott, D. W. (1968). El papel de espejo de la madre y la família en el desarrollo del niño. En Realidad y Juego. (pp.147-156). Barcelona. Gedisa, 2009.

Winnicott, D.W. (1971). Realidad y Juego. Barcelona. Gedisa, 2009.

Original recibido con fecha: 18-12-2016 Revisado: 15-2-2017 Aceptado: 28-2-2017

\section{CelR Vol. 11 (1) - Febrero 2017 ISSN 1988-2939 - www.ceir.info}

(c) Derechos reservados/Copyright de Clínica e investigación Relacional y los autores. Prohibida la reproducción total o parcial sin autorización expresa. Este material es para uso científico y profesional exclusivamente y puede contener información clínica sensible. Los editores no se responsabilizan de los contenidos de los autores. Dirigir las consultas sobre derechos y autorizaciones a ceir@psicoterapiarelacional.es 